Table 1

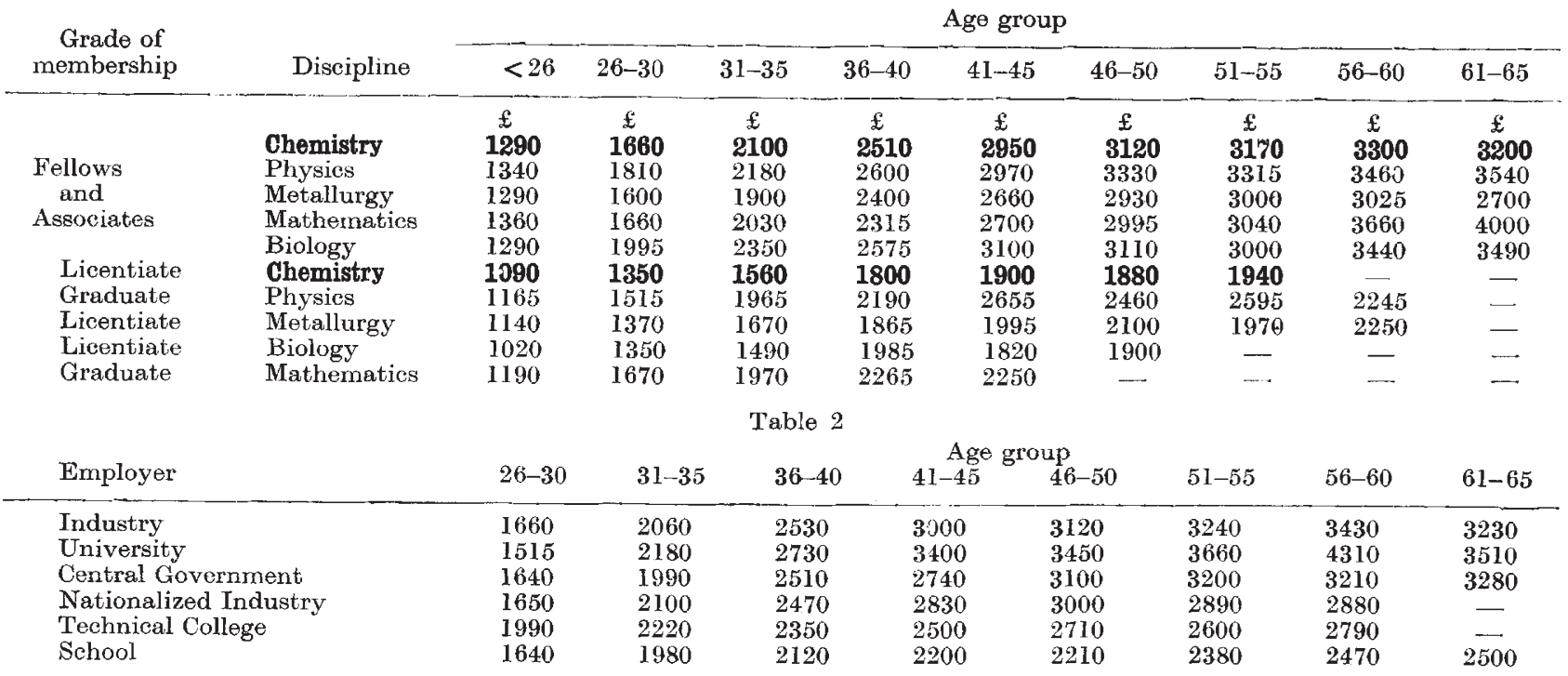

In both grades of membership the physicists and mathematicians appear to climb fastest up the ladder of material success, the mathematicians earning more at earlier ages but being leapfrogged by the physicists in the mid-forties. In the sixties the biologists seem to do better than anyone, the salary of $£ 4,000$ being the median of 42 members. The numbers who responded to the survey include 2,855 biologists and 14,366 chemists (figures for other disciplines are not yet available).

Table 2 gives the median salaries by sector of fellows and associates of the Royal Institute of Chemistry.

A possibly surprising aspect of the survey is that after the age of 30 chemists in industry earn consistently less than their colleagues at universities, which presumably indicates that there is no market shortage. The same is true for physicists, as far as can be judged from the four summary graphs so far issued by the Institute of Physics and the Physical Society. From the age of 30 , associate physicists earn a steady $£ 200$ more in universities than in industry. Graduates of the institute are paid pretty much the same in universities and industry, whereas fellows earn more in universities except between the ages of 44 and 52 when industrial

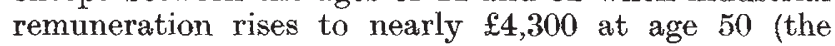

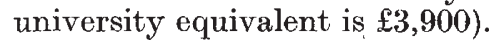

Median salary of chemists has risen by a factor of about 1.8 in all age groups since 1956 , and by $1 \cdot 1$ sirce 1965 . There has been no significant movement of chemists into industry since 1965. The rate for the job, as far as chemists are concerned, does not vary widely between different regions of Great Britain and Ireland.

\section{SPACE DIPLOMACY}

\section{ESRO Up, ELDO Down}

IT has been a mixed week for European science diplomacy.

The most telling event was the news from the ESRO council meeting on October 8-9 that one of the two large TD satellite projects cancelled in April has been rescued. Escalating costs (above the grossly optimistic contractual price of $£ 7$ million) and Italian intransigence over an economy plan to provide one satellite for the price of two had brought about deadlock. ESRO's constitution provides for "special projects" to be undertaken if there is support from two thirds of the member countries. This has been the mechanism adopted for continuing with the stellar TD, intended to be chronologically second and promising to be a very sophisticated and exciting experimental package for the early 1970s. Terms for ESRO special projects are that only those countries taking part pay and ESRO acts as manager. At last week's meeting it turned out that nine out of the ten ESRO countries wanted to take part-Italy is still not interested-so the shares will be very little larger than if it were a full ESRO programme. (The final cost to Britain is expected to be about $\mathfrak{i} 4$ million out of a total bill of about $£ 20$ million.) The degree of agreement represents a triumph for ESRO's new Director-General, Professor H. Bondi, who has personally led the rescue negotiations. There was warm praise from the Science Research Council last week for the way ESRO has handled this affair. This is a symbolic as well as a tangible recovery.

Apart from the TDs (which take their name from their adopted American Thor-Delta launchers), ESRO had no satellite project scheduled beyond this year. The organization was formed to support projects that no individual member could afford on its own. That means satellites either larger or more sophisticated than the British Ariel series on the Reuch Diamant launched payloads. The TDs were both. It remains to be seen if anything can be salvaged from the solar physics TD, due to catch the end of the solar maximum for which several of the experiments, including the British, had been built. There is a well conceived future programme of ESRO satellite launchings ready, but this awaits commitment to a new and increased budget by ESRO countries at the Bonn European Space Conference (ESC) in November.

Also linked with the ESC is the report of the further committee on a long-term European space programme called for by the inconclusive ELDO ministerial meeting on October 1-2 (see Nature, 220, 109; 1968). It is due to report to the ministers the day before the 
Bonn Conference (November 11). The committee started work in Brussels on Wednesday (October 16). Grudgingly, the British Government finally decided to send a delegate. Nominations had to be in by Saturday, 12 th, and decision was reached only at the last moment -late Friday - after 10 days of Whitehall discussions on the point following the failure of the British move at the ELDO ministerial meeting in Paris. This aimed to link an ELDO solution with discussions for a larger framework of European technological collaboration. The German resolution adopted, with British and Australian abstentions, limited the Brussels committee's work to European space problems. The Ministry of Technology, the front-runner in these manoeuvres, seems only concerned that the collapse of ELDO (and the waste incidentally of at least $£ 170$ million spent by the British taxpayer alone) should not be blamed on Britain. It has an uphill task. Impressions from the Paris meeting were that the five continental member governments of ELDO already had a blueprint for Brussels so that the committee would be little more than a rubber stamp. The Government's face-saving efforts would not be helped if Britain made no effort to modify the talks by joining in.

\section{UNIVERSITIES}

\section{Science Surveyed}

OfFICral circles in Oxford might well be advised by some of the student opinions aired in the survey of conditions and courses carried out by Zenith, the university science magazine, and the University Scientific Society (Static or Dynamic? . . a Survey of Oxford Undergraduate Science, 3s. from Zenith, University Museum, Oxford).

Answers to a questionnaire sent to a third of all science undergraduates revealed several areas of dissatisfaction with courses and syllabuses, although not all felt as strongly as the physicists and engineers, of whom a fifth and a third respectively would prefer to have gone to another university. Many of the complaints concerned practical courses, which are often badly organized and uninteresting, frequently in the first year being little more than a repetition of school work. Many experiments in physics consist solely of reading instructions, making the apparatus work and putting numbers into formulae, which is time consuming and not necessarily instructive.

There was considerable enthusiasm for a general broadening of courses. Forty per cent of chemistry undergraduates would prefer to do a joint course if this was possible. The most popular subject for a joint course was economics (one seventh of chemists would like to be able to do this). Other suggestions were business studies, philosophy, psychology or more biologically slanted subjects. Sixty-one per cent of physiologists would also like courses in non-scientific subjects, especially German, Russian, economics and sociology, provided they were voluntary and without examinations. Perhaps the new courses in physics and philosophy, and mathematies and philosophy will go some way to serve this need for broader courses.

There is also considerable criticism of lecturers, many of whom are said not to be up to their tasks, being unable to hold an audience or to communicate ideas concisely and coherently. Apart from laziness, bad lecturers was the only reason given by students for not attending lectures. The most popular remedy for this was fewer lectures-given by the best lecturers-and more informal classes and seminars to supplement tutorials.

\section{RARE EARTHS \\ Semiconductors by Guslight}

A NEGLECTED corner of the periodic table, the rare earths, came into the news on Monday when Thorium Ltd started operation at Widnes of its $£ 500,000$ plant for purifying rare earth oxides. It is the largest rare earth plant in the world, and will substantially increase world supplies of neodymium, lanthanum and praseodymium. The plant depends on a countercurrent distribution process. An aqueous solution of rare earth nitrates flows through a series of mixing chambers against an opposite current of tributylphosphate: by recycling material through the plant, levels of 99.99 per cent purity are easily obtained.

The whole operation provides something of a textbook model for the translation of research into production. Other methods of refining rare earths-fractional precipitation and ion exchange-are not fully satisfactory and, in 1961, the research staff of Thorium Ltd -25 per cent of the company's personnel-began to investigate the possibilities of countercurrent distribution. By 1964 they had a commercially viable process, and they began to have an edge in the world market over their main competitors in the United States and Japan. Some vigorous work in the patent office has made it possible for them to sell the process, under licence, to firms in the United States and Japan, under an agreement which forbids these firms from exporting any of their production outside their own territories. The process earned the firm a Queen's Award for Technology last year, and the overseas business that came in its wake earned them a Queen's Award for Exports this year. Since 1965 the firm's turnover has doubled while its exports have quadrupled.

Thorium Ltd's new plant has a productive capacity far in excess of current needs, but the firm's marketing staff are confident that sales will expand in step with production. The optical industry already uses lanthanum oxide in high quality lenses, while praseodymium oxide is the basis of a brilliant yellow pigment for ceramics. Too much neodymium oxide is made at the moment, but the unique optical properties of the material arouse the company's hopes that glass manufacturers will take it up as a decolorizing agent. It has a sharp absorption band which accurately cancels the yellow colour of iron traces in glass.

The ore that feeds the plant, bastnaesite imported from California, is a source of more exotic rare earths as well, and Thorium Ltd has managed to find markets for some of these. Europium is apparently unassailable as a red phosphor in colour television tubes, yttrium is used in laser garnets and gadolinium has potential as a quenching metal in nuclear reactors.

The electronics industry is a willing accomplice in the efforts of Thorium Ltd to find uses for even the more obscure of the flock of elements. The bizarre optical and magnetic properties of the rare earths will no doubt be a strong selling point. At the same time, 